\title{
An in vitro study on the influence of viscosity and frequency of application of fluoride/tin solutions on the progression of erosion of bovine enamel
}

\author{
Letícia Oba Sakae ${ }^{\mathrm{a}}$, Sávio José Cardoso Bezerra ${ }^{\mathrm{a}}$, Samira Helena João-Souza ${ }^{\mathrm{a}}$, \\ Alessandra Buhler Borges ${ }^{\mathrm{b}}$, Idalina V. Aoki ${ }^{\mathrm{c}}$, Ana Cecília Côrrea Aranha ${ }^{\mathrm{a}}$, Taís Scaramucci ${ }^{\mathrm{a}, *}$ \\ a Department of Restorative Dentistry, University of São Paulo, School of Dentistry, Av. Prof. Lineu Prestes 2227, Cidade Universitária, São Paulo, SP, 05508-000, Brazil \\ ${ }^{\mathrm{b}}$ Department of Restorative Dentistry, Institute of Science and Technology, São Paulo State University, Av. Eng. Francisco José Longo, 777, Jardim São Dimas, São José dos \\ Campos, SP, 12245-000, Brazil \\ ${ }^{\mathrm{c}}$ Department of Chemical Engineering, Polytechnic School, University of São Paulo. Av. Prof. Luciano Gualberto, travessa 3, 380, Cidade Universitária, São Paulo, SP, \\ 05508010, Brazil
}

\section{A R T I C L E I N F O}

\section{Keywords:}

Dental erosion

Solution

Viscosity

Fluoride

Tin

\begin{abstract}
A B S T R A C T
Objective: To evaluate the influence of the viscosity and frequency of application of solutions containing fluoride (F) and stannous chloride $\left(\mathrm{SnCl}_{2}\right)$ on enamel erosion prevention.

Design: Bovine enamel specimens were randomly distributed into 12 groups $(\mathrm{n}=10)$, according to the following study factors: solution (C: deionized water; F: $500 \mathrm{ppm} \mathrm{F}^{-}$; F $+\mathrm{Sn}: 500 \mathrm{ppm} \mathrm{F}^{-}+800 \mathrm{ppm} \mathrm{Sn}^{2+}$ ); viscosity (low and high); and frequency of application (once and twice a day). Specimens were submitted to an erosive cycling model, consisting of $5 \mathrm{~min}$ immersion in $0.3 \%$ citric acid, followed by $60 \mathrm{~min}$ exposure to a mineral solution. This procedure was repeated $4 \times /$ day, for 5 days. Treatment with the experimental solutions was performed for $2 \mathrm{~min}, 1 \times /$ day or $2 \times /$ day. Enamel surface loss (SL) was determined by optical profilometry. Data were analyzed by 3-way ANOVA and Tukey tests $(\alpha=0.05)$.

Results: There were significant differences between the levels of the factor solution ( $<<.001)$, viscosity $(\mathrm{p}<.001)$ and in the interaction between solution and viscosity $(\mathrm{p}=.01)$. Regarding solution, the mean $\mathrm{SL} \pm$ standard deviation for the groups was F + Sn $(4.90 \pm 1.12)<\mathrm{F}(7.89 \pm 1.19)<\mathrm{C}(14.20 \pm 1.69)$. High viscosity solutions demonstrated less SL than low viscosity; however, only when applied once a day $(\mathrm{p}<.001)$. Applying the solutions twice a day yielded lower SL than once a day, but only for the low viscosity solutions $(\mathrm{p}=.003)$.

Conclusions: Under the conditions of this short-term in vitro experiment, it could be concluded that increasing the viscosity of the oral rinse solutions reduced enamel loss by erosion; however, this effect was small and only observed when the solutions were applied once a day.
\end{abstract}

\section{Introduction}

The frequent contact of non-bacterial acids with the tooth surfaces can lead to dental erosion (Eccles, 1978), which has become a condition of growing concern among dental practitioners and researchers (Lussi \& Carvalho, 2014). Data from in vitro and in situ studies have shown that topical fluoride application can protect the dental substrates against erosive attacks (Ganss, Neutard, von Hinckeldey, Klimek, \& Schlueter, 2010; Scaramucci, Borges, Lippert, Frank, \& Hara, 2013; Scaramucci et al., 2015; Wiegand et al., 2010). So far, promising results have been obtained with the use of stannous fluoride or the combination of fluoride and tin added as separate compounds (Ganss, Hardt et al., 2010; Scaramucci et al., 2015). This was attributed to the deposition of calcium fluoride-like material and other metal-rich deposits on the tooth surfaces, which would temporally protect the tissue against demineralization (Huysmans, Young, \& Ganss, 2014; Magalhães, Wiegand, Rios, Buzalaf, \& Lussi, 2011). Additionally, it was demonstrated that tin can incorporate into enamel and dentin, thus reducing their solubility (Ganss, Hardt et al., 2010; Schlueter, Hardt et al., 2009).

However, the effectiveness of the treatment with fluoride compounds may be limited, especially under frequent acid attacks. One way to overcome this limitation is by high frequency of application of the

* Corresponding author at: Department of Restorative Dentistry, University of São Paulo, School of Dentistry, Av. Prof. Lineu Prestes 2227, Cidade Universitária, Butantã, São Paulo, SP, 05508-000, Brazil.

E-mail addresses: leticia.sakae@usp.br (L.O. Sakae), saviobezerra@usp.br (S.J.C. Bezerra), samira.souza@usp.br (S.H. João-Souza), alessandra@fosjc.unesp.br (A.B. Borges), idavaoki@usp.br (I.V. Aoki), acca@usp.br (A.C.C. Aranha), tais.sca@usp.br (T. Scaramucci). 
fluoridated products (Huysmans et al., 2014). Nevertheless, when delivered in vehicles that allow frequent applications, such as mouthrinses and dentifrices, fluoride does not sustain much substantivity in the oral cavity (Mason, Shirodaria, Sufi, Rees, \& Birkhed, 2010). Although the anti-erosive effect of a solution containing $500 \mathrm{ppm}$ of fluoride and $800 \mathrm{ppm}$ of tin was previously observed with a single daily application (Ganss, Neutard et al., 2010), it was further demonstrated that applying this solution twice a day could improve its efficacy (da Silva, RamosOliveira, Mantilla, \& de Freitas, 2017). It was hypothesized that the use of solutions with higher viscosity could improve the retention of fluoride and metal cations on tooth surfaces (Pini, Lima, Lovadino, Ganss, \& Schlueter, 2016), and this could ultimately allow a lower frequency of application.

To the authors' knowledge, there is little information available on how the viscosity of fluoridated solutions would influence their protection against dental erosion. One investigation evaluated the effect of increasing the viscosity of a fluoride plus tin-containing solution using varieties of chitosan with different molecular weights (Pini et al., 2016). The authors observed that the more viscous solution presented a higher anti-erosive effect, however, it should be noted that chitosan is a positively charged polymer that can behave not only as a thickening agent, but also as film-forming molecule (Tharanathan \& Kittur, 2003). In this sense, it is unknown whether the improved anti-erosive effect observed could be related only to the increased viscosity of the solution. The use of non-ionic thickening polymers could help clarify this issue, as it is unlikely that they would strongly bind to hydroxyapatite (AykutYetkiner, Wiegand, Bollhalder, Becker, \& Attin, 2013), although the possibility of a weaker interaction, such as physical adsorption should not be disregarded (Umoren \& Eduok, 2016).

In view of the foregoing, the aim of this present study was to evaluate the interaction between the viscosity and frequency of application of solutions containing fluoride and stannous chloride on protection against enamel erosion. Our null hypotheses were: 1 . There would be no difference in enamel surface loss with the use of fluoridated solutions with different viscosity; 2 . There would be no difference in enamel loss by applying the fluoridated solutions once or twice daily.

\section{Materials and methods}

\subsection{Study design}

This in vitro study was conducted with a completely randomized experimental design, with 3 experimental factors: experimental solutions (control, $\mathrm{F}$ and $\mathrm{F}+\mathrm{Sn}$ ), viscosity (low and high), and frequency of application (once or twice a day). The solutions were tested in an erosive cycling model, using enamel specimens from bovine incisors $(n=10)$. The response variable was enamel surface loss (in $\mu \mathrm{m})$, measured with an optical profilometer at the end of cycling.

\subsubsection{Specimen preparation}

Bovine incisors were stored in $0.1 \%$ thymol solution (SigmaAldrich, St Louis MO, USA), under refrigeration at $4{ }^{\circ} \mathrm{C}$, until the experiment began. Enamel fragments $(4 \mathrm{~mm} \times 4 \mathrm{~mm} \times 2 \mathrm{~mm})$ were prepared, using an automatic cutting machine (Isomet 1000 Precision Saw, Buehler, Lake Bluff, IL, USA). The fragments were embedded in acrylic resin (Varidur, Buehler) and the resulting blocks were ground flat with abrasive discs (400, 1200, 2400 and 4000 grit; Fepa P, Buehler), in a polishing machine (Ecomet, Buehler), under constant water cooling. At the end of the polishing procedure, the specimens were submitted to an ultrasonic bath with deionized water for $3 \mathrm{~min}$.

\subsubsection{Surface curvature assessment}

After preparation of the specimens, they were submitted to profilometric analysis to select specimens with a curvature $<0.3 \mu \mathrm{m}$. This analysis was performed with an optical profilometer (Proscan 2100, Scantron, Venture Way, Tauton, UK). The instrument sensor scanned an area that was $2 \mathrm{~mm}$ long (X-axis) and $1 \mathrm{~mm}$ wide (Y-axis), located at the center of the specimen. The equipment was set to go through 200 steps in the $\mathrm{X}$-axis, with each step measuring $0.01 \mathrm{~mm}$. In the Y-axis, there were 20 steps measuring $0.05 \mathrm{~mm}$ each. The curvature was calculated based on the subtraction of the mean height of the future test area from the mean height of the two reference surfaces using a dedicated software (Proscan Application software v. 2.0.17). The surfaces of 120 specimens with maximum initial curvature of $0.3 \mu \mathrm{m}$ and without cracks or any other defects, were protected with unplasticized polyvinyl chloride (UPVC) tapes, leaving a central area of $4 \mathrm{~mm} \times 1 \mathrm{~mm}$ exposed for the subsequent tests.

\subsubsection{Experimental solutions}

For the $\mathrm{F}$ solutions, the concentration of $\mathrm{F}$ was chosen based on previous studies (Ganss, Hardt et al., 2010; Schlueter, Neutard, von Hinckeldey, Klimek, \& Ganss, 2010). The solution was formulated with $\mathrm{NaF}$ (Sigma-Aldrich $\mathrm{Co}$ ) and the $\mathrm{pH}$ was adjusted to 4.5 with $\mathrm{HCl}$ solution. For the $\mathrm{F}+\mathrm{Sn}$ solutions, a commercially available mouthrinse was used (Elmex Erosion Protection, GABA Schweiz AG, Colgate-Palmolive Co, Therwil, Switzerland; $500 \mathrm{ppm} \mathrm{F}^{-}, 125 \mathrm{ppm} \mathrm{F}^{-}$as AmF and $375 \mathrm{ppm} \mathrm{F}^{-} \mathrm{NaF} ; 800 \mathrm{ppm} \mathrm{Sn}^{2+}$, as $\mathrm{SnCl}_{2} ; \mathrm{pH} 4.5$ ). All the $\mathrm{pH}$ values were determined by using a calibrated $\mathrm{pH}$ electrode (HI2221, Hanna Instruments, Woonsocket, RI, USA).

The viscosity of the solutions was adjusted with polymer hydroxyethyl cellulose (HEC; Natrosol, Hercules Incoporated, Wilmington, DE, USA) and expressed in mPa.s. A preliminary test was performed to evaluate the concentration of HEC needed to achieve solutions with high viscosity. Although more viscous, these solutions had to be compatible with the mode of use of a mouthrinse, e.g., it had to be possible to swish the solution around the mouth. To determine the HEC concentration, solutions containing increasing HEC concentrations $(0.1 \%$, $0.15 \%, 0.2 \%, 0.25 \%, 0.3 \%, 0.35 \%$ and $0.4 \%$ ) were evaluated regarding their dynamic viscosity. For this measurement, a SV-10 vibro viscometer (A\&D, Toshima-ku, Tokyo, Japan) was used. The measurements were performed at $24^{\circ} \mathrm{C}$.

The dynamic viscosity of the solutions containing $0.1 \%, 0.15 \%$, $0.2 \%, 0.25 \%, 0.3 \%, 0.35 \%, 0.4 \%$ and $0.45 \%$ were, respectively: 2.70 ; $4.04 ; 5.99 ; 8.24 ; 12.02 ; 17.51 ; 24.71$; and 37.54 . Based on these results (and on our premise that the solution had to be able to be swished around the mouth), we opted to use the concentration of $0.35 \%$ HEC in the high viscosity solutions ( $17.51 \mathrm{mPa}$.s of dynamic viscosity).

After adding the HEC to the high viscosity solutions, the viscosity of all experimental solutions was determined by using a similar methodology. Detailed description of the experimental groups is shown in Table 1.

\subsubsection{Erosive cycling}

The specimens were randomly allocated into the 12 experimental groups $(n=10)$, and submitted to a 5 -day erosive cycling. During each day, the specimens were individually immersed in $4 \mathrm{ml}$ of $0.3 \%$ citric acid solution (natural $\mathrm{pH}$ of 2.6) for $5 \mathrm{~min}$, followed by $60 \mathrm{~min}$ exposure to $4 \mathrm{ml}$ of a mineral solution (Scaramucci et al., 2013). This was repeated 4 times per day. For the groups treated with the test solutions

Table 1

Detailed description of the experimental groups.

\begin{tabular}{ll}
\hline & Description \\
\hline Solutions & C: control (deionized water; natural $\mathrm{pH})$ \\
& F: sodium fluoride solution $(\mathrm{NaF} ; 500 \mathrm{ppm} \mathrm{F} ; \mathrm{pH}=4.5)$ \\
& F + Sn: Elmex Erosion Protection $(500 \mathrm{ppm} \mathrm{F}$ as NaF and AmF; \\
& $800 \mathrm{ppm} \mathrm{Sn}$ as $\left.\mathrm{SnCl}_{2} ; \mathrm{pH} 4.5\right)$ \\
Viscosity & Low (water viscosity, no hydroxyethyl cellulose added) \\
& High (with addition of $0.35 \%$ hydroxyethyl cellulose) \\
Frequency & Once a day \\
& Twice a day
\end{tabular}


twice a day, exposure to the solutions $(4 \mathrm{ml})$ was performed $30 \mathrm{~min}$ after the first and the last erosive challenges, for 2 min (João-Souza et al., 2017). In the groups in which immersion in the treatment solutions was performed once a day, the specimens were immersed $30 \mathrm{~min}$ after the first erosive challenge, for $2 \mathrm{~min}$ as well. Overnight, the specimens were stored in the mineral solution, which was changed daily when the experimental procedures began. The other solutions were replaced after each time the specimens were exposed to them.

\subsubsection{Surface loss determination}

At the end of the 5-day erosive cycling, the tapes were removed from the specimen surfaces, which were then analyzed by an optical profilometer (Proscan 2100). A central area on the specimen surfaces, measuring $2 \mathrm{~mm}$ in length on the $\mathrm{X}$-axis and $1 \mathrm{~mm}$ on the $\mathrm{Y}$-axis, was scanned. The scan included both reference areas (protected by the tapes) and the test area that received the treatments. The sensor was set to travel 200 steps of $0.01 \mathrm{~mm}$ distance on the X-axis, and 20 steps of $0.05 \mathrm{~mm}$ on the Y-axis. A specific software (Proscan Application software v. 2.0.17) calculated the surface loss by subtracting the mean height of the treated surface from the mean height of the two reference areas.

\subsubsection{Statistical analysis}

Surface loss (SL) data were tested for normal distribution and homoscedasticity with Shapiro-Wilk and Brown-Forsythe tests, respectively. Comparison among groups was performed with 3-way ANOVA and Tukey tests. The significance level was set at $5 \%$. The software used for the analysis was SigmaPlot 13 (Systat Software Inc., Chicago Illinois, USA).

\section{Results}

Dynamic viscosity of the solutions tested is shown in Table 2. The dynamic viscosity values for the solutions without HEC were observed to be quite similar to the viscosity of the commercially available mouthrinse, Elmex Erosion Protection (F + Sn solution), and both were also similar to the dynamic viscosity of the distilled water. The addition of $0.35 \%$ HEC increased the viscosity from approximately sixteen to eighteen fold.

ANOVA detected significant differences between the levels of the factors experimental solutions ( $\mathrm{p}<.001$ ), viscosity ( $\mathrm{p}<.001$ ), and in the interaction between viscosity and frequency of application $(p=.01)$. There were no significant differences between the levels of the factor frequency of application $(\mathrm{p}=.098)$ and in the other interactions $(\mathrm{p}>.05)$.

Table 3 shows the mean SL values (SD) for all experimental groups. Tukey test showed that for the factor solutions, $\mathrm{F}+\mathrm{Sn}$ presented the lowest SL value ( $\mathrm{p}<.001$ ), followed by $\mathrm{F}$ ( $\mathrm{p}<.001$ ), and the control $(\mathrm{p}<.001)$. Regarding the factor viscosity, high viscosity solutions presented lower SL than those with lower viscosity $(\mathrm{p}<.001)$. Relative to the interaction between viscosity and frequency of application, in the once a day application groups, the high viscosity solutions presented significantly lower SL than the low type $(\mathrm{p}<.001)$. In the twice a day application groups, there was no significant difference between the viscosities $(\mathrm{p}=.551)$. For the solutions with low viscosity, twice a

Table 2

Dynamic viscosity of the solutions.

\begin{tabular}{ll}
\hline Solutions & Dynamic viscosity (in mPa s) \\
\hline Control low viscosity & 0.98 \\
Control high viscosity & 16.61 \\
F low viscosity & 0.87 \\
F high viscosity & 18.10 \\
F + Sn low viscosity & 1.11 \\
F + Sn high viscosity & 16.60 \\
\hline
\end{tabular}

day application showed significantly lower SL than once a day application $(\mathrm{p}=.003)$. For the solutions with high viscosity, there was no significant difference in applying the solutions once or twice a day $(\mathrm{p}=.502)$.

\section{Discussion}

In this study, increasing the viscosity of the solutions was able to significantly reduce enamel loss, but this effect was small and only observed for the groups in which the solutions were applied once a day. Thus, our first null hypothesis could only be partially rejected. Possibly, the solutions with higher viscosity remained in prolonged contact with the enamel surface, helping to hamper the contact with acid during subsequent erosive challenges. In the twice a day application, the more intensive regimen of fluoride and tin application could have led to a degree of protection that was not further improved by the higher viscosity. These theories, however, warrant further investigations using more clinically relevant study models.

The magnitude of the interaction between polymers and the substrates depends on their macromolecular weights, chemical composition, as well as molecular and electronic structures (Umoren \& Eduok, 2016). The polymer HEC is a neutral molecule, but in acid solutions, it can acquire a slightly positive center, allowing a certain interaction with the negative sites at the enamel surface (low energy bonding of van der Waals forces). In addition, due to the long chain length of its molecule, HEC can also physically interact with the enamel surface, providing some coverage (Umoren \& Eduok, 2016). However, due to the weak nature of its interaction with enamel, it is conceivable that the protection offered by this polymer would not have much resistance to acid challenges. In view of this, we believe that the viscosity effect in reducing the clearance of the fluoridated solutions on enamel would be more important than the adsorption of the polymer itself.

The fact that the low viscosity fluoridated solutions showed minor superior effects in the twice a day application allowed us to partially reject our second null hypothesis. Although the reason for this effect is unclear, we may suggest that this could be related to a cumulative effect of the deposits created by F and F + Sn from both applications. For the $\mathrm{F}+\mathrm{Sn}$ solutions, its improved effect against erosion is consistent with several past reports (Ganss, Hardt et al., 2010; Scaramucci et al., 2015; Schlueter, Klimek, \& Ganss, 2011; Schlueter et al., 2010). A previous study observed a high retention of tin at the enamel surface even after several acid challenges (Schlueter, Hardt et al., 2009). Tin was also observed to be capable of incorporating into the enamel during cycling; and the more tin that was incorporated, the thicker was this stannousmodified enamel structure, which in turn was associated with a lower level of substance loss (Schlueter, Hardt et al., 2009).

There is not much data available relative to the effect of the frequency of application of $\mathrm{F}$ or $\mathrm{F}+\mathrm{Sn}$-containing solutions on erosion protection. Despite variations in the study design and in the characteristics of the solutions tested, so far, the results for the F solutions have been controversial. While studies have found significant protection with F solutions applied only once a day (Ganss, Hardt et al., 2010; Schlueter, Klimek, \& Ganss, 2009), others were unable to observe this effect even when applying the solutions twice a day (da Silva et al., 2017; Schlueter et al., 2010; Souza, Lima, Comar, Buzalaf, \& Magalhães, 2014). As regards the F + Sn solutions, studies have tested its application once (Schlueter et al., 2011), twice (Schlueter et al., 2010), and even three times a day (Scaramucci et al., 2015), with promising results against erosive demineralization. In one previous in vitro investigation, an $\mathrm{AmF} / \mathrm{NaF} / \mathrm{SnCl}_{2}$ solution $(1500 \mathrm{ppm} \mathrm{F}$ and $2800 \mathrm{ppm} \mathrm{Sn)} \mathrm{was} \mathrm{able} \mathrm{to} \mathrm{reduce} \mathrm{erosion} \mathrm{in} \mathrm{more} \mathrm{than} 80 \%$ when applied twice and six times a day (Schlueter, Duran, Klimek, \& Ganss, 2009). In another study, it was observed in situ that an $\mathrm{AmF} / \mathrm{NaF} / \mathrm{SnCl}_{2}$ solution (500 ppm F and $800 \mathrm{ppm} \mathrm{Sn)} \mathrm{was} \mathrm{only} \mathrm{capable} \mathrm{of} \mathrm{exhibiting}$ significant protective effect against enamel erosion in relation to the control when it was applied twice a day (da Silva et al., 2017). 
Table 3

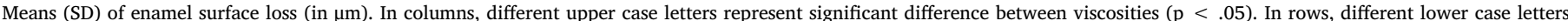
denote significant differences among solutions $(\mathrm{p}<.05)$.

\begin{tabular}{|c|c|c|c|c|c|c|}
\hline & \multicolumn{3}{|l|}{ Once a day } & \multicolumn{3}{|l|}{ Twice a day } \\
\hline & Control & $\mathrm{F}$ & $\mathrm{F}+\mathrm{Sn}$ & Control & $\mathrm{F}$ & $\mathrm{F}+\mathrm{Sn}$ \\
\hline Low viscosity & $15.17(1.81) \mathrm{Aa}^{*}$ & 8.67 (1.13)Ab & $5.83(0.42) \mathrm{Ac}^{*}$ & $14.67(1.12) \mathrm{Aa}^{*}$ & $7.89(1.25) \mathrm{Ab}^{*}$ & 4.15 (1.05)Ac \\
\hline High viscosity & $13.09(1.76) \mathrm{Ba}$ & $7.54(1.18) \mathrm{Bb}$ & $4.83(1.15) \mathrm{Bc}$ & $13.87(1.12) \mathrm{Aa}$ & $7.48(0.73) \mathrm{Ab}$ & 4.47 (0.97)Ac \\
\hline
\end{tabular}

* represents significant difference between once a day and twice a day applications $(\mathrm{p}<.05)$.

This study was designed in accordance with the recommendations proposed for erosion studies (Shellis, Ganss, Ren, Zero, \& Lussi, 2011). The polymer used to increase the solution's viscosity is a biocompatible, non-ionic and water-soluble ether used in industries as a thickener, protective colloid, binder, stabilizer, and suspending agent in a variety of applications, such as water-based paints, adhesives, emulsion polymers, toothpaste, cosmetics and building products (Kadajji \& Betageri, 2011). Since temperature can affect the viscosity of the solutions (Kestin, Khalifa, Sookiazian, \& Wakeham, 1978), the entire experiment was conducted at room temperature, of $24 \pm 1{ }^{\circ} \mathrm{C}$, including the experimental solutions. Considering that we opted to use a commercially available product for the $\mathrm{F}+\mathrm{Sn}$ solution (Elmex Erosion Protection), in order to simulate the same fluoride concentration and $\mathrm{pH}$ of this product, we had to formulate the F solution, which in turn did not have excipient components contained in the commercial product. It should be noted that a mineral solution was used for cycling; therefore, the effect of the salivary pellicle could not be simulated. This would be interesting to test in further studies, as the presence of the salivary pellicle could influence the interaction of the solutions with the enamel surface, especially in the presence of polymers. Another point was the effect of tooth brushing, which was also not simulated. The mechanical action of tooth brushing could potentially influence the anti-erosive effect of film-forming agents, as it could accelerate their removal from the enamel surface (Scaramucci et al., 2016). It should also be pointed out that, in this experiment, more than one enamel fragment were obtained from the same tooth. Although the specimens were randomly allocated among the groups, the possibility of the presence of multiple specimens from the same tooth in one group was not considered in the statistical analyses. In view of these considerations, care should be taken when extrapolating the results of this study to the clinical scenario. As far as the test solutions were concerned, a possible drawback related to the high viscosity would be their increased stickiness, which may cause discomfort when using them to rinse the mouth.

\section{Conclusion}

Under the conditions of this short-term in vitro experiment, it could be concluded that increasing the viscosity of the oral rinse solutions reduced enamel loss by erosion; however, this effect was small and only observed when the solutions were applied once a day.

\section{Conflict of interest}

None.

\section{Acknowledgments}

The authors appreciate the support of São Paulo Research Foundation (FAPESP; grant \# 2015/12014-1).

\section{References}

Aykut-Yetkiner, A., Wiegand, A., Bollhalder, A., Becker, K., \& Attin, T. (2013). Effect of acidic solution viscosity on enamel erosion. Journal of Dental Research, 92(3), 289-294. http://dx.doi.org/10.1177/0022034512473115.
Eccles, J. D. (1978). The treatment of dental erosion. Journal of Dentistry, 6(3), 217-221. http://dx.doi.org/10.1016/0300-5712(78)90245-2.

Ganss, C., Hardt, M., Lussi, A., Cocks, A.-K. K., Klimek, J., \& Schlueter, N. (2010). Mechanism of action of tin-containing fluoride solutions as anti-erosive agents in dentine - An in vitro tin-uptake, tissue loss, and scanning electron microscopy study. European Journal of Oral Sciences, 118(4), 376-384. http://dx.doi.org/10.1111/j. 1600-0722.2010.00742.x.

Ganss, C., Neutard, L., von Hinckeldey, J., Klimek, J., \& Schlueter, N. (2010). Efficacy of a tin/fluoride rinse: A randomized in situ trial on erosion. Journal of Dental Research, 89(11), 1214-1218. http://dx.doi.org/10.1177/0022034510375291.

Huysmans, M.-C., Young, A., \& Ganss, C. (2014). The role of fluoride in erosion therapy. Monographs in Oral Science, 25, 230-243. http://dx.doi.org/10.1159/000360555.

João-Souza, S. H., Bezerra, S. J. C., de Freitas, P. M., de Lima, N. B., Aranha, A. C. C., Hara, A. T., et al. (2017). In situ evaluation of fluoride-, stannous- and polyphosphate-containing solutions against enamel erosion. Journal of Dentistry, 63, 30-35. http://dx.doi.org/10.1016/j.jdent.2017.05.014.

Kadajji, V. G., \& Betageri, G. V. (2011). Water soluble polymers for pharmaceutical applications. Polymers, 3(4), 1972-2009. http://dx.doi.org/10.3390/polym3041972.

Kestin, J., Khalifa, H. E., Sookiazian, H., \& Wakeham, W. A. (1978). Experimental investigation of the effect of pressure on the viscosity of water in the temperature range $10-150{ }^{\circ} \mathrm{C}$. Berichte Der Bunsengesellschaft Für Physikalische Chemie, 82(2), 180-188. http://dx.doi.org/10.1002/bbpc.197800008.

Lussi, A., \& Carvalho, T. S. (2014). Erosive tooth wear: A multifactorial condition of growing concern and increasing knowledge. Monographs in Oral Science, 25, 1-15. http://dx.doi.org/10.1159/000360380.

Magalhães, A. C., Wiegand, A., Rios, D., Buzalaf, M. A. R., \& Lussi, A. (2011). Fluoride in dental erosion. Fluoride and the Oral Environment, 22, 158-170. http://dx.doi.org/10. $1159 / 000325167$.

Mason, S. C., Shirodaria, S., Sufi, F., Rees, G. D., \& Birkhed, D. (2010). Evaluation of salivary fluoride retention from a new high fluoride mouthrinse. Journal of Dentistry, 38(Suppl. 3), http://dx.doi.org/10.1016/S0300-5712(11)70006-9.

Pini, N. I. P., Lima, D. A. N. L., Lovadino, J. R., Ganss, C., \& Schlueter, N. (2016). In vitro efficacy of experimental chitosan-containing solutions as anti-erosive agents in enamel. Caries Research, 50(3), 337-345. http://dx.doi.org/10.1159/000445758.

Scaramucci, T., Borges, A. B., Lippert, F., Frank, N. E., \& Hara, A. T. (2013). Sodium fluoride effect on erosion-abrasion under hyposalivatory simulating conditions. Archives of Oral Biology, 58(10), 1457-1463. http://dx.doi.org/10.1016/j. archoralbio.2013.06.004.

Scaramucci, T., Borges, A. B., Lippert, F., Zero, D. T., Aoki, I. V., \& Hara, A. T. (2015). Anti-erosive properties of solutions containing fluoride and different film-forming agents. Journal of Dentistry, 43(4), 458-465. http://dx.doi.org/10.1016/j.jdent.2015 01.007.

Scaramucci, T., João-Souza, S. H., Lippert, F., Eckert, G. J., Aoki, I. V., \& Hara, A. T. (2016). Influence of toothbrushing on the antierosive effect of film-forming agents. Caries Research, 50(2), 104-110. http://dx.doi.org/10.1159/000443619.

Schlueter, N., Neutard, L., von Hinckeldey, J., Klimek, J., \& Ganss, C. (2010). Tin and fluoride as anti-erosive agents in enamel and dentine in vitro. Acta Odontologica Scandinavica, 68(3), 180-184. http://dx.doi.org/10.3109/00016350903555395.

Schlueter, N., Klimek, J., \& Ganss, C. (2011). Efficacy of tin-containing solutions on erosive mineral loss in enamel and dentine in situ. Clinical Oral Investigations, 15(3), 361-367. http://dx.doi.org/10.1007/s00784-010-0386-x.

Schlueter, N., Duran, A., Klimek, J., \& Ganss, C. (2009). Investigation of the effect of various fluoride compounds and preparations thereof on erosive tissue loss in enamel in vitro. Caries Research, 43(1), 10-16. http://dx.doi.org/10.1159/000189702.

Schlueter, N., Hardt, M., Lussi, A., Engelmann, F., Klimek, J., \& Ganss, C. (2009). Tincontaining fluoride solutions as anti-erosive agents in enamel: An in vitro tin-uptake, tissue-loss, and scanning electron micrograph study. European Journal of Oral Sciences, 117(4), 427-434. http://dx.doi.org/10.1111/j.1600-0722.2009.00647.x.

Schlueter, N., Klimek, J., \& Ganss, C. (2009). Efficacy of an experimental tin-f-containing solution in erosive tissue loss in enamel and dentine in situ. Caries Research, 43(6), 415-421. http://dx.doi.org/10.1159/000252974.

Shellis, R. P., Ganss, C., Ren, Y., Zero, D. T., \& Lussi, A. (2011). Methodology and models in erosion research: Discussion and conclusions. Caries Research, 45(Suppl. 1), 69-77. http://dx.doi.org/10.1159/000325971.

Souza, B. M., Lima, L. L. M., Comar, L. P., Buzalaf, M. A. R., \& Magalhães, A. C. (2014). Effect of experimental mouthrinses containing the combination of NaF and TiF4 on enamel erosive wear in vitro. Archives of Oral Biology, 59(6), 621-624. http://dx.doi. org/10.1016/j.archoralbio.2014.03.008.

Tharanathan, R. N., \& Kittur, F. S. (2003). Chitin-the undisputed biomolecule of great potential. Critical Reviews in Food Science and Nutrition, 43(1), 61-87. http://dx.doi. org/10.1080/10408690390826455. 
Umoren, S. A., \& Eduok, U. M. (2016). Application of carbohydrate polymers as corrosion inhibitors for metal substrates in different media: A review. Carbohydrate Polymers, 140, 314-341. http://dx.doi.org/10.1016/j.carbpol.2015.12.038.

Wiegand, A., Hiestand, B., Sener, B., Magalhães, A. C., Roos, M., \& Attin, T. (2010). Effect of TiF4, ZrF4, HfF4 and AmF on erosion and erosion/abrasion of enamel and dentin in situ. Archives of Oral Biology, 55(3), 223-228. http://dx.doi.org/10.1016/j. archoralbio.2009.11.007.

da Silva, C. V., Ramos-Oliveira, T. M., Mantilla, T. F., \& de Freitas, P. M. (2017)

Frequency of application of $\mathrm{AmF} / \mathrm{NaF} / \mathrm{SnCl} 2$ solution and its potential in controlling human enamel erosion progression: An in situ study. Caries Research, 51(2), 141-148. http://dx.doi.org/10.1159/000455051. 